\title{
Tuberculosis Amigdalina con foco pulmonar primario: Reporte de un caso
}

\author{
Juan Antonio Lugo Machado¹, Edwin Canche Martin²
}

\section{RESUMEN}

La tuberculosis en una enfermedad infecciosa que afecta a varios órganos y tejidos del cuerpo, teniendo mayor tropismo por afección pulmonar, gastrointestinal y sistema nervioso central, e incluso tejido óseo, sin embargo se han reportado casos aislados de afección a otras estructuras en diferentes reportes de casos, de la misma forma en el que se presenta un paciente que acudió con síntomas a nivel del tejido amigdalino y posteriormente se evidenció involucramiento pulmonar, considerándose a la infección amigdalina del presente caso como una tuberculosis amigdalar secundaria con foco primario a nivel pulmonar. (Horiz Med 2015; 15(3): 61-63)

Palabras clave: Tuberculosis, Amígdalas. (Fuente: DeCS BIREME).

Tonsillar tuberculosis, with primary pulmonary focus: A Case Report

\section{ABSTRACT}

Tuberculosis is an infectious disease that affects various organs and tissues, with greater tropism for lung disease, gastrointestinal and central nervous system tissue and even bone. However isolated cases of affection to other structures have been reported,just like this patient who came with symptoms in the tonsils and subsequently, lung involvement became apparent. Theton sillar infection in this case was considered a secondary tuberculosis with primary focus in the lungs. (Horiz Med 2015; 15(3): 61-63)

Key words: Tuberculosis, Tonsills, Odinofagia. (Source: MeSH NLM).

Médico Cirujano Especialista en Otorrinolaringología, Sub especialista en Otorrinolaringología Pediátrica; Médico Adscrito de Otolaringología Especialidades No2, Centro Médico Nacional del Noroeste, IMSS, cd. Obregón, Sonora, México

2 Médico Residente de Otorrinolaringología; Especialidades No2, Centro Médico Nacional del Noroeste, IMSS, cd. Obregón, Sonora, México 


\section{INTRODUCCIÓN}

La tuberculosis (TB) es una enfermedad infecciosa causada más comúnmente por Mycobacterium tuberculosis y Mycobacterium bovis. Sus presentaciones clínicas son variables y a menudo pasa desapercibido el diagnóstico. Afecta principalmente al pulmón.

A pesar de la contigüidad de la mucosa y el contacto de las secreciones pulmonares con la amígdala palatina, la incidencia de tuberculosis amigdalina es baja y su diagnóstico es un reto. El diagnóstico temprano es esencial para el tratamiento médico y los resultados son favorables.

La tuberculosis extra pulmonar representa aproximadamente el $25 \%$ de la morbilidad tuberculosa en general. La tuberculosis extrapulmonar (TBE), más común es la tuberculosis de los ganglios linfáticos, mientras que otras formas son: pleural, ósea del SNC, abdominal, genito-urinario, miliar y pericarditis tuberculosa. La tuberculosis de la cavidad oral es poco común y en las amígdalas son extremadamente raras.

\section{CASO CLÍNICO}

Se presenta el caso de un paciente masculino de 43 años, Originario de Navojoa, Sonora, México, de ocupación jornalero, con antecedentes de tabaquismo desde los 20 años, consumiendo 10 cigarros diarios, alcoholismo positivo desde los 18 años, resto de los antecedentes negados.

Inicia en las 2 semanas previas a su primera consulta con disfagia a sólidos, que posteriormente progresa a líquidos, odinofagia y disfonía con pérdida de peso, sin referir fiebre. Exploración Física: Orofaringe con Ulcera amigdalina derecha (Fig. 1), Adenopatía en área ganglionar II de cuello. Gabinete: Tele de tórax con infiltrado retículo nodular difuso (Fig. 2). BAAR en esputo 3 muestras: Negativo. Biopsia incisional de amígdala Reporte histopatológico: Tejido granulomatoso, células multinucleadas sin datos de malignidad, BAAR (-). Fig. 3.

Broncoscopía con lavado y cepillado bronquial, con reporte de BAAR (+) y negativo a malignidad.

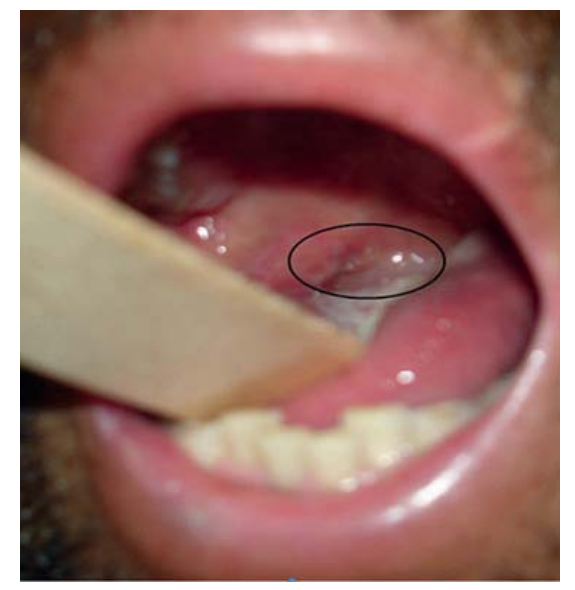

Figura 1. Orofaringe con Úlcera amigdalina derecha

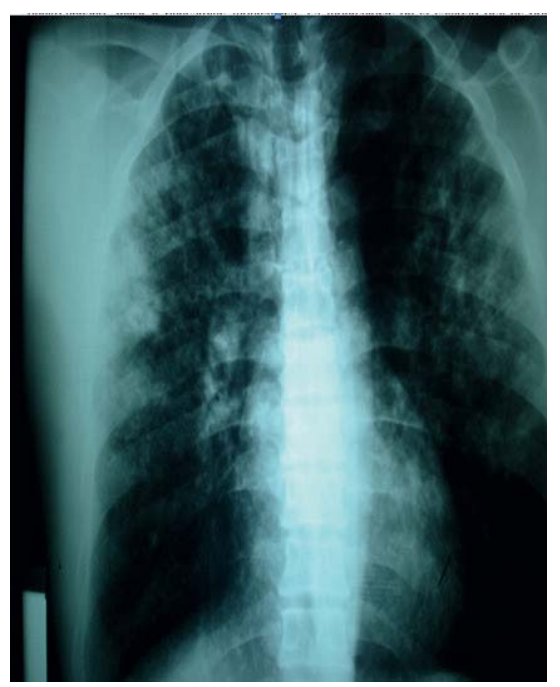

Figura 2. Tele de tórax con infiltrado retículo nodular difuso

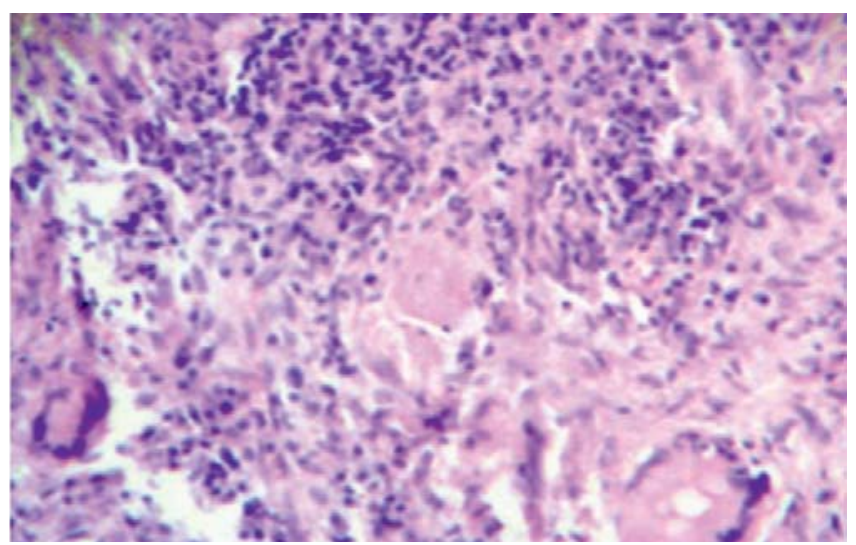

Figura 3. Tejido granulomatoso, células multinucleadas sin datos de malignidad 


\section{DISCUSIÓN}

La tuberculosis es una enfermedad infecciosa sistémica, la cual afecta principalmente al pulmón. Ésta entidad se mantiene como infección que afecta los estratos socio culturales bajos, donde el hacinamiento, mala nutrición y pobre escolaridad, son factores epidemiológicos facilitadores para ello.

En lo que respecta a las afecciones extra pulmonares del tracto respiratorio superior, la amígdala y nasofaringe han sido consideradas como formas raras. La incidencia de tuberculosis parafaringea y amigdalina es estimada en un $0.1 \%$ a $0.6 \%$ (1) y en $0.05 \%-1.5 \%$ de todos los pacientes con TB (2).

El síntoma más común de presentación es la disfonía y en un alto porcentaje también se presenta disfagia, odinofagia, tos y pérdida de peso, el dolor por la infiltración faríngea y amigdalina es un síntoma muy importante referido por el paciente.

La patogenia es usualmente por auto inoculación con esputo infectado, aunque también esta descrita la forma sanguínea (3). El diagnóstico se basa en el PPD, Rx tórax, identificación del bacilo por baciloscopia, biopsia y cultivos (4-6).

El diagnóstico diferencial incluye úlceras traumáticas y aftosas, enfermedades hematológicas, actinomicosis, sífilis, granuloma de la línea media, enfermedad de Wegners y malignidad (6). Es importante realizar una evaluación del posible foco de infección tuberculosa, ya que el sitio principal es de vía aérea inferior, también es fundamental esclarecer otros sitios involucrados.

El tratamiento de TB amigdalina al igual que la pulmonar es básicamente médico basado en tres y/ o cuatro combinaciones de isoniazida, rifampicina, pirazinamida.

En conclusión, la tuberculosis amigdalina es una enfermedad de muy baja frecuencia, que en países en vías de desarrollo puede sugerirse ante un cuadro de odinofágia persistente y la disfagia, con mala respuesta al tratamiento médico. Consideramos importante buscar de forma dirigida los sitios primarios más frecuentes de diseminación, como pulmón, gastrointestinal, entre otros.

\section{REFERENCIAS BIBLIOGRÁFICAS}

1. Bath AP, O'Flynn P, Gibbin KP. Nasopharyngeal tuberculosis. J Laryngol Otol 1992; 106: 1079-1080.

2. Pedrol E, Estruch R, Barcelo J, et al: Tonsillar and pharyngeal tuberculosis in a patient without HIV antibodies. J Infect Dis 1989;159: 598-562.

3. Eng L, Lu SY, Yang C, Chen W. Oral tuberculosis. Oral surgery, oral medicine, oral pathology. 1996:81: 415-420.

4. Chumakov FI, Gerasimenko NV. Isolated tuberculosis of pharyngeal and palatine tonsil Vestn Otorrinolaringol, 2000, 2, 58.

5. Hajioff D, Snow Mil, Thaker H, Wilson J A, Primary tuberculosis of the posterior oropharyngeal wall. J Laryngol Otol, 1999; 113(11): 1029.

6. Gupta KB, Tandon S, Jaswal TS, Singh S. Tuberculosis of tonsil with unusual presentation. Ind. Tub, 2001; 48:223-224

7. Ricciardiello F, Martufi S, Cardone M. Otorhinolaryngology-related tuberculosis. J Acta Otorhinolaryngol Ital. 2006;26:38-42

8. S. Kant, S. K. Verma, and Sanjay, "Isolated tonsil tuberculosis," Lung India 2008; 25: 163-164.

9. L. S. Farer, A. M. Lowell, and M. P. Meader, "Extra pulmonary tuberculosis in USA," American Journal of Epidemiology 1992; 109: 205-217.

10. H. F. Wilkinson, "A study of ten thousand pairs of tonsils, with special reference to the presence of cartilage, bone, tuberculosis and bodies suggestive of actinomycosis," Archives of Otolaryngology 1929; 10 (2): 127-151.

11. Jana $U$, Mukherjee $S$. "Tuberculosis of tonsil-a rare siteinvolvement," Indian Journal of Otolaryngology and Head and Neck Surgery 2003; 55 (2): 119-120.

\section{Fuente de financiamiento}

Este estudio ha sido autofinanciado por el autor.

\section{Conflictos de interés}

El autor declara no tener ningún conflicto de interés

\section{Correspondencia:}

Juan Antonio Lugo Machado

Dirección: Huisaguay s/n Colonia Del Valle, Cd. Obregón, Sonora - México

Teléfono: +6441559891

Correo electrónico: otorrinox@gmail.com

Recibido: 21 de Junio de 2015

Aprobado: 06 de Agosto de 2015 